\title{
Performance Analysis of a Helical Savonius Wind Turbine with Modified Rotor
}

\author{
Ahmed S. Saad $^{*}$, Ali M. AbdelSalam ${ }^{\dagger}$, I. M. Sakr ${ }^{\ddagger}$ W. A. El-Askary ${ }^{\S}$
}

\begin{abstract}
This study aims to investigate numerically the performance of a helical Savonius wind rotor with a twist angle of $45^{\circ}$. The twist is performed on a modified profile of the rotor blade. The power coefficient $\left(\mathrm{C}_{\mathrm{p}}\right)$, the torque coefficient $\left(\mathrm{C}_{\mathrm{T}}\right)$, and the static torque coefficient $\left(\mathrm{C}_{\mathrm{TS}}\right)$ are computed under a constant aspect ratio of 1.0 and overlap ratio of 0.15 . The numerical results presented in this paper are obtained using the three-dimensional incompressible unsteady Reynolds-Averaged Navier-Stokes equations along with the RNG k- $\varepsilon$ turbulence model. A comparison between the present helical Savonius wind turbine of modified rotor and the helical Savonius wind turbine of conventional rotor shows better performance for the present modification. The maximum power coefficient and the maximum torque coefficient for the present helical modified rotor are 0.22 and 0.41 , respectively.
\end{abstract}

Keywords: Numerical study, modified rotor, modified helical rotor with twist, maximum power coefficient.

\section{Introduction}

In recent years, the growth in energy demand, depletion of fossil fuel sources and increase in environmental pollution caused by the fossil fuel burning lead to increasing the importance of using the renewable energy sources. Wind energy is one of the renewable energy sources for green economical energy generation. Wind turbines are broadly classified into two categories based on the axis of rotation: Horizontal Axis Wind Turbine (HAWT) and Vertical Axis Wind Turbine (VAWT). HAWTs have high efficiency compared to the VAWTs and are used for medium to large scale electricity generation. However, VAWTs have some advantages over the HAWTs such as simple construction, lower installation, and maintenance costs, low operating wind speed, relatively good self-starting ability, low noise level and less wear on moving parts. Also, it can accept the wind from any direction. Thus, VAWTs are useful for installation as a low-cost, small-scale decentralized energy generation device [1-3].The Savonius rotor is a VAWT developed by the Finnish engineer, Savonius, [4]. This rotor was formed by cutting a cylinder into two halves along the central plane to resemble the cross section of the letter ' $\mathrm{S}$ '. The Savonius rotor can be used for pumping water, driving an electrical generator and agitating the water to keep stock ponds ice-free during the winter. It can be used in buildings for heating, ventilation, and air-conditioning (HVAC) purposes, $[5,6]$.

Demonstrator, Dept. of Mech. Power Eng., Faculty of Engineering, Shebin El-Kom, Menoufia University,

Egypt; Ahmed.s.saad1992@gmail.com

Assistant Professor, Faculty of Engineering, Shebin El-Kom, Menoufia University, Egypt.

Assistant Professor, Faculty of Engineering, Shebin El-Kom, Menoufia University, Egypt.

Professor, Faculty of Engineering, Shebin El-Kom, Menoufia University, Egypt. 
Numerous investigations have been performed on the Savonius rotor to study its performance characteristics. The effects of various design parameters of Savonius wind rotor have been studied experimentally and numerically such as aspect ratio, overlap ratio, blade profile, rotor angle, and the number of blades, the presence or absence of rotor end plates and the influence of Reynolds number, [7-11].

The influence of the overlap ratio of Savonius wind rotor was studied experimentally by Fujisawa, [12] and numerically by Akwa et al., [13]. The results showed that the maximum performance occurs at an overlap ratio of 0.15. Mohamed et al., [14] performed a numerical analysis on two and three bladed Savonius rotors. The results showed that the power coefficient of the two-bladed rotor is higher than the three-bladed rotor. It is observed that the performance of the rotor has been enhanced significantly by using end plates in the rotor design. The existence of end plates has been investigated and reported a high power coefficient, $[8,15,16]$. As a result of the previous investigations, the diameter of these end plates $\mathrm{D}_{\mathrm{O}}$ has to be taken as 1.1D (rotor diameter) for the rotor aspect ratio of 1.0 , for improving the Savonius rotor performance, [17, 18]. Gad et al., [19] studied the effect of modifying the Savonius rotor blade using seven shapes of the blades in addition to the conventional Savonius rotor. The results showed that the performance of the rotor increased by using these modifications of the rotor blade. One of the new developed polynomial blade shapes has the highest values of average torque and average power coefficients compared to the other shapes. Kamoji et al., [18] tested a helical Savonius rotor with a twist of $90^{\circ}$ in an open jet wind tunnel. The results of this study were compared with the results of the conventional Savonius rotor and it was observed that the static torque coefficients at all the rotor angles for helical rotor are positive unlike for conventional Savonius rotor, there are several rotor angles at which static torque coefficient is negative. Damak et al., [20] experimentally investigated the performance of the helical Savonius rotor with a twist of $180^{\circ}$. The results showed that the helical geometry gives better performances than the conventional one. Lee et al., [21] performed an investigation on a helical rotor with twist angles of $0^{\circ}, 45^{\circ}$, $90^{\circ}$, and $135^{\circ}$. This investigation showed that the maximum $C_{p}$ occurs at a twist angle of $45^{\circ}$. However, the value of the power coefficient $C_{p}$ at twist angles of $90^{\circ}$ and $135^{\circ}$ was found to be lower than that at $0^{\circ}$ but the maximum $C_{p}$ appeared to be similar.

In the present work, a helical Savonius rotor with a twist angle of $45^{\circ}$ is introduced. The twist is performed on a modified profile of the rotor blade. The comparison between the performance of this modified helical rotor with twist and other three rotors is numerically conducted. The three rotors are, conventional rotor, conventional helical rotor with twist, modified rotor and modified helical rotor with twist. This rotor could provide positive static torque coefficient at all rotor angles.

\section{Design Parameters and Tested Rotors}

Various parameters are used to design a helical Savonius wind turbine blade, as shown in Fig.1. The main design parameters include the aspect ratio (AR), overlap ratio $(\delta)$, rotor angle $(\theta)$, and twist angle $(\varphi)$.

The aspect ratio (AR) is defined as the rotor height $(\mathrm{H})$ relative to the rotor diameter $(\mathrm{D})$, which is given by

$$
\mathrm{AR}=\frac{H}{D}
$$




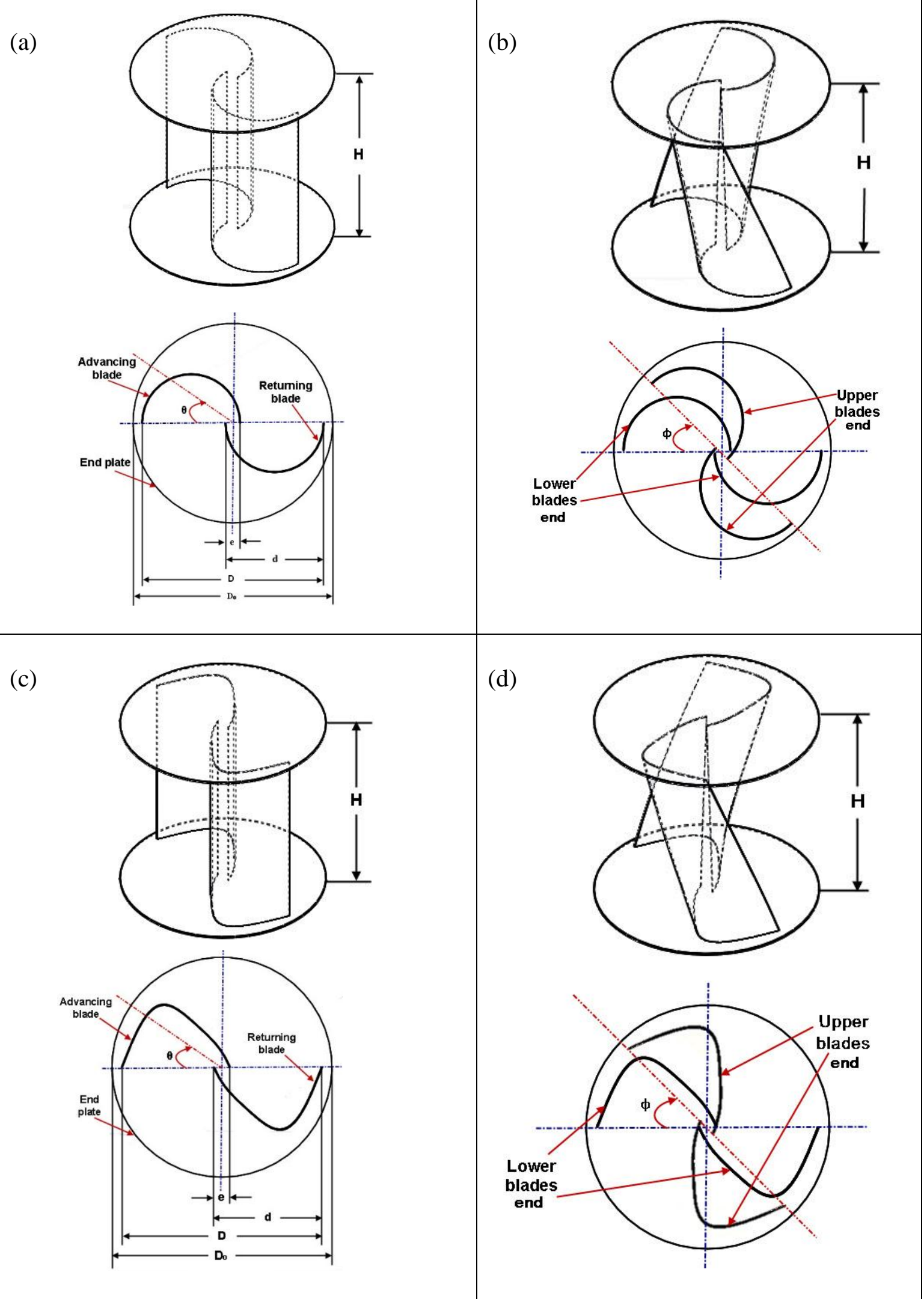

Fig.1. Isometric and top view of Savonius Rotors covered in this study:

(a) Conventional rotor, (b) conventional helical rotor with twist, (c) Modified rotor and (d) Modified helical rotor with twist 
Overlap ratio $(\delta)$ is defined as the ratio of overlap distance between the two blades of the rotor (e) to the blade chord length (d) and is given by

$$
\delta=\frac{e}{d}
$$

Rotor angle $(\theta)$ and twist angle $(\varphi)$ are the angles of rotation of the rotor about its axis and the angle between the lower and upper ends of the rotor respectively, as shown in Fig.1.

The present study is performed on four Savonius rotors: the conventional Savonius rotor (conventional rotor), the helical Savonius of conventional rotor with a twist angle of $45^{\circ}$ (conventional helical rotor with twist), modified Savonius rotor (modified rotor) and helical Savonius of modified rotor with a twist angle of $45^{\circ}$ (modified helical rotor with twist), as shown in Fig.1. The helical Savonius of conventional rotor and helical Savonius of modified rotor are $45^{\circ}$ twist angle $(\varphi)$. The blades of the modified rotor have polynomial profile instead of the semi-circular profile in the conventional ones, as shown in Fig.2. Equation representing the profile of the modified blades is

$Y=0.55-0.62 X-1.7 X^{2}+4.14 X^{3}-1.51 X^{4}-7.57 X^{5}$

where $X$ is measured from the center of the blade, [19].

Helix can be defined as a curve generated by a marker moving vertically at a constant velocity on a rotating cylinder (at a constant angular velocity). The blade retains its profile shape from the bottom $\left(0^{\circ}\right)$ to the top $\left(45^{\circ}\right)$. The four rotors have a diameter (D) of $40 \mathrm{~cm}$ and $40 \mathrm{~cm}$ height $(\mathrm{H})$ with 0.15 overlap ratio $(\delta)$. The diameter of end plates $\left(\mathrm{D}_{\mathrm{o}}\right)$ is taken to be 1.1 of rotor diameter (D).

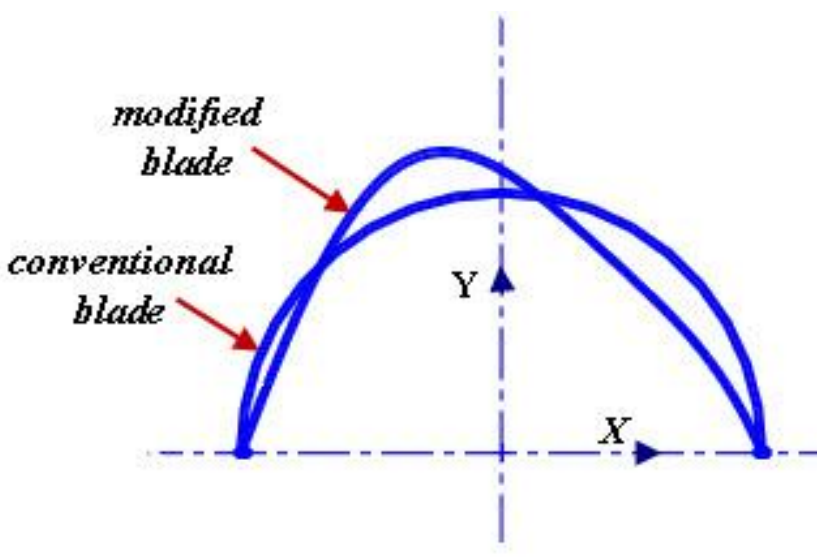

Fig.2. Blade profiles of conventional and modified rotors

\section{Numerical Analysis}

In the present study, ANSYS Fluent 15.0, industrial CFD code, has been used to compute the flow field around the wind turbine. It calculates the complicated flow structure based on the finite volume method (FVM) of the Navier - Stokes equations, for resolving the problems associated with the interaction between the complicated on-coming wind flow and the rotating blades. The Unsteady Reynolds Averaged Navier-Stokes equations are solved using the SIMPLE algorithm. The sliding mesh model, [22] is selected to represent the rotation of the turbine rotor. The turbulence is created by four turbulence models which are the standard $\mathrm{k}-\varepsilon$, realizable $\mathrm{k}-\varepsilon$, RNG $\mathrm{k}-\varepsilon$ and SST $\mathrm{k}-\omega$. The complete description of the turbulence models used is found in, [22]. 
For appropriate analysis, the overall domain is divided into two zones, the first one is the rotating zone and the second is the remaining zone of the studied domain, as shown in Fig.3. The two zones are separated by an interface and the rotating zone is allowed to rotate with different values of revolutions while the second zone is still fixed. The three-dimensional CAD model of the computational domain has been completed using SolidWorks program, and the ANSYS ICEM program has been utilized for generating the computational grids. The main grid shapes of the rotating rotor and surrounding outer domain are shown in Fig.4. The inlet boundary is fed with a uniform velocity of $6 \mathrm{~m} / \mathrm{s}$ at $5 \mathrm{D}$ upstream of the rotor, and the outlet boundary is considered as an atmospheric pressure at the exit of the domain. The top and lateral sides of the domain are far from the center of the rotor of about 5D. Thus, both of them are sufficiently far from the wake core and, to be treated using "Neumann" boundary condition, in which the gradient of a variable normal to the boundary is set to zero $\left(\frac{\partial \varphi}{\partial n}=0\right.$, where $\varphi$ is any variable and $\mathrm{n}$ is normal to the boundary). The "Wall" boundary condition is applied to the bottom boundary of the computational domain. A grid independent study has been performed utilizing unstructured mesh of suitable grid sizes with six different grid resolutions $(0.4,0.95,1.4,2,3.75$ and 4.8 million cells) in the simulations as shown in Fig.5. It is found that there is no variation in all parameters while increasing the grid over 2 million cells. Hence, the grid in the range of 2 million cells has been retained for all computations presented in this paper. For such a value of grid number, the non-dimensional near-wall grid distance $(\mathrm{y}+)$ is less than 5 over the rotor blades.

Holding the solution of conservation equations and the chosen turbulence model, the rotor torque $(\mathrm{T})$ can be calculated by integrating the forces resulting from the pressure $\left(F_{f}^{\text {pressure }}\right.$ ) and shear $\left(F_{f}^{\text {shear }}\right)$ on the rotor multiplied by the local torque arm $(l)$ as given by the following equation, [13, 22]

$$
\begin{aligned}
& \mathrm{T}=\sum_{f}\left(\mathrm{~F}_{\mathrm{f}}^{\text {pressure }}+\mathrm{F}_{\mathrm{f}}^{\text {shear }}\right) l=\sum_{f}\left[\left(\mathrm{P}_{\mathrm{f}}-\mathrm{P}_{\mathrm{ref}}\right) A_{f}+\left(-\tau_{f} \cdot A_{f}\right)\right]_{(\text {advancing })} \cdot l \\
& -\sum_{f}\left[\left(\mathrm{P}_{\mathrm{f}}-\mathrm{P}_{\text {ref }}\right) A_{f}+\left(-\tau_{f} \cdot A_{f}\right)\right]_{(\text {returning })} l
\end{aligned}
$$

where $\mathrm{P}_{\mathrm{f}}, \mathrm{P}_{\text {ref }}$ and $\tau_{f}$ are the pressure, the reference pressure, and shear stress, respectively and $A_{f}$ is the face area.

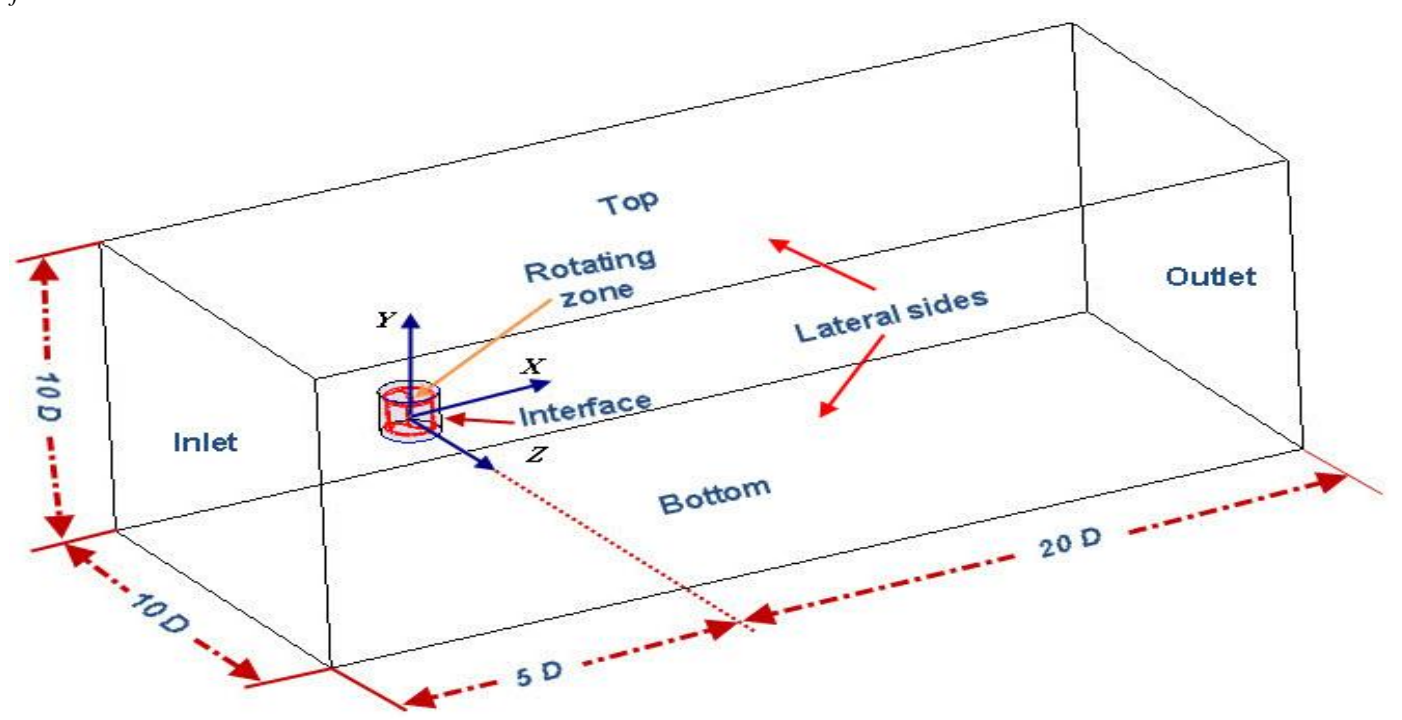

Fig.3. Schematic representation of the computational domain 
(a)

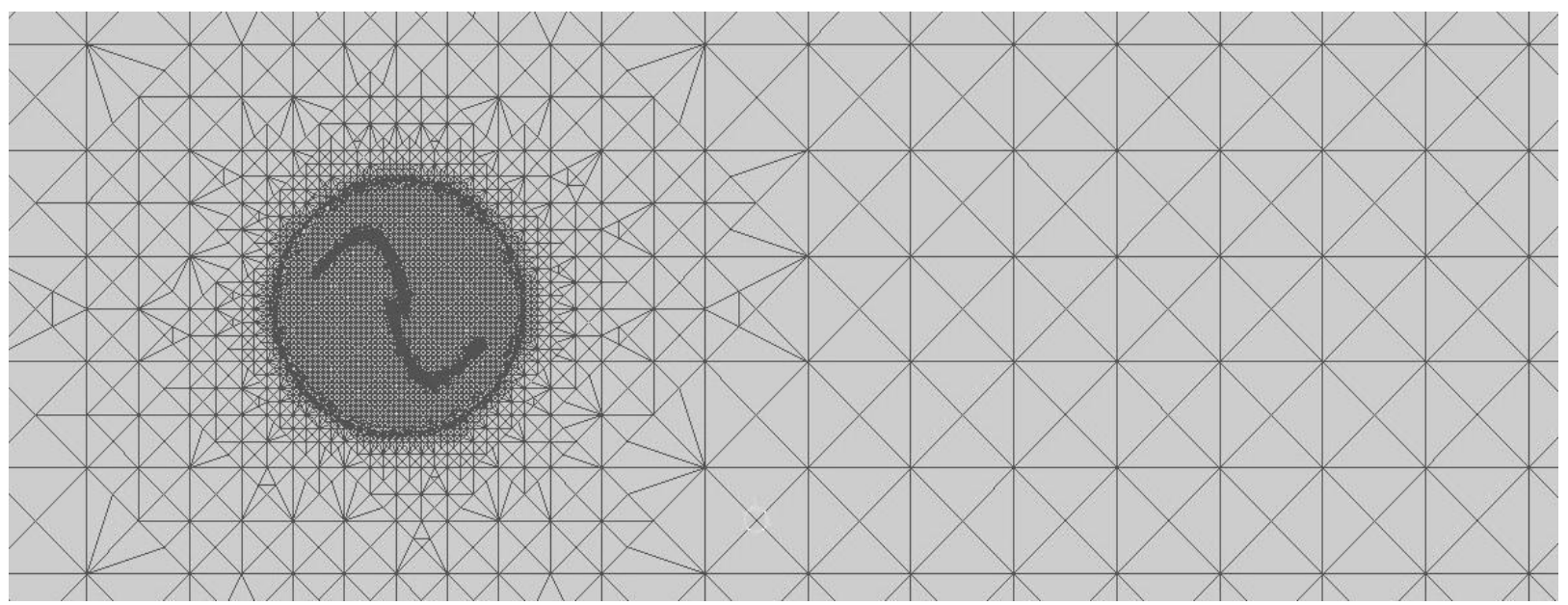

(b)

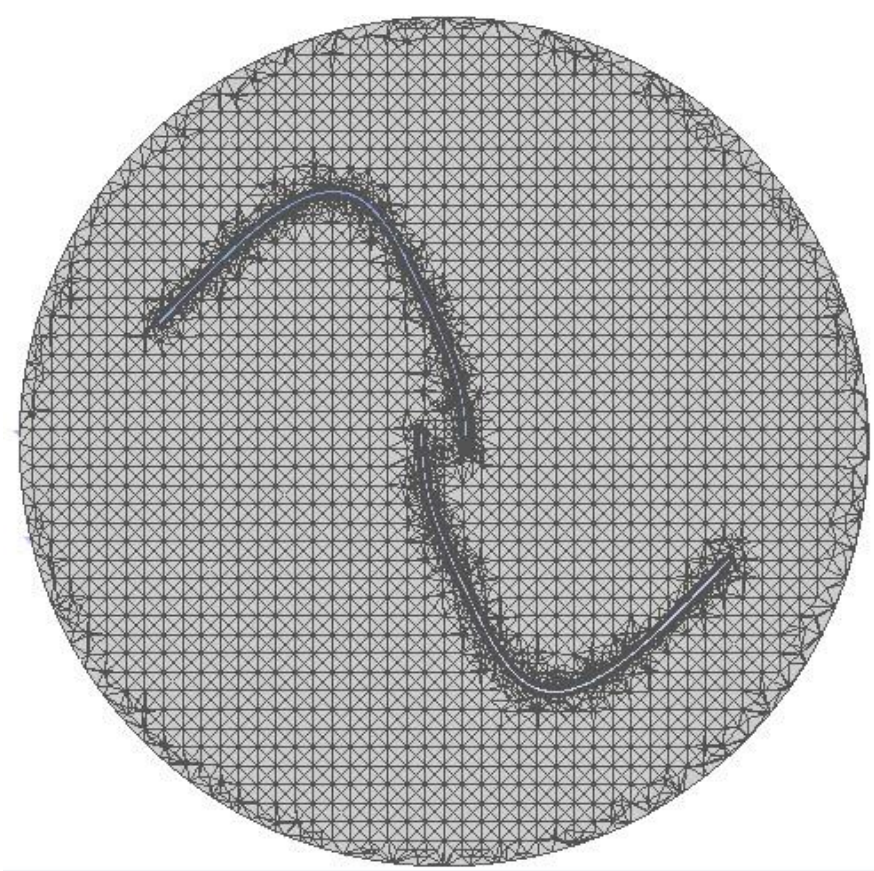

Fig. 4. Mesh of the computational domain (a) Horizontal center plane across the rotor (b) close-up of the rotor mesh

The static torque, dynamic torque and power coefficients can be computed, respectively from the following equations:

$$
\begin{aligned}
& \mathrm{C}_{\mathrm{TS}}=\frac{4 \mathrm{~T}_{\mathrm{S}}}{\rho \mathrm{V}^{2} \mathrm{D}^{2} \mathrm{H}} \\
& \mathrm{C}_{\mathrm{T}}=\frac{4 \mathrm{~T}}{\rho \mathrm{V}^{2} \mathrm{D}^{2} \mathrm{H}} \\
& \mathrm{C}_{\mathrm{P}}=\frac{\text { Protor }_{\text {rotor }}}{\text { Pavailable }}=\frac{\mathrm{T} \omega}{0.5 \rho \mathrm{AV}}=\frac{\mathrm{T}(\omega \mathrm{D} / 2)}{0.5 \rho \mathrm{AV}(\mathrm{D} / 2)}=\mathrm{C}_{\mathrm{T}} \lambda
\end{aligned}
$$

where $T_{S}$ and $T$ are the static and dynamic torques generated by the rotor, respectively. 
$\mathrm{P}_{\text {rotor }}$ is the mechanical power generated by the rotating rotor with rotation speed $\omega$ and $\mathrm{P}_{\mathrm{available}}$ is the available power in the incoming wind. $\rho$ is the density of the air and $\mathrm{V}$ is the incoming free stream wind speed. $\mathrm{A}$ is the rotor projected area defined as $\mathrm{A}=\mathrm{DH}$ and $\lambda$ is the tip speed ratio which defined as the ratio between rotor tip speed $u$ and the free stream wind speed $\mathrm{V}$, given by $\lambda=\frac{u}{V}$.

\section{Results and Discussion}

To validate the numerical results and select the suitable turbulence model predicting the performance of Savonius rotor, comparisons between results of the conducted turbulence models and experimental results of Fujisawa, [12] are presented in Fig. 6. The turbulence models performed are, the standard $\mathrm{k}-\varepsilon$, the realizable $\mathrm{k}-\varepsilon$, the RNG $\mathrm{k}-\varepsilon$ and the SST $\mathrm{k}-\omega$. The rotor tested by Fujisawa was $30 \mathrm{~cm}$ diameter with overlap ratio $(\delta)$ of 0.15 and aspect ratio (AR) of 1.0. The upstream wind speed was $6 \mathrm{~m} / \mathrm{s}$. It is observed from Fig. 6 that all the four turbulence models overestimate the $C_{P}$ for $\lambda$ beyond 0.6 , and underestimate the $C_{P}$ for $\lambda$ of value high than 0.8 . Although the realizable $\mathrm{k}-\varepsilon$ and RNG $\mathrm{k}-\varepsilon$ models seem to show better prediction, the assessment of the turbulence models from plots is difficult. In the present work, the coefficient of correlation $\left(\mathrm{R}^{2}\right)$ is used to determine which turbulence model is more accurate in comparison with experimental results of Fujisawa, [12]. The coefficient of correlation $\left(\mathrm{R}^{2}\right)$ is computed using Eq. (9) as given by Maindonald and Braun, [23].

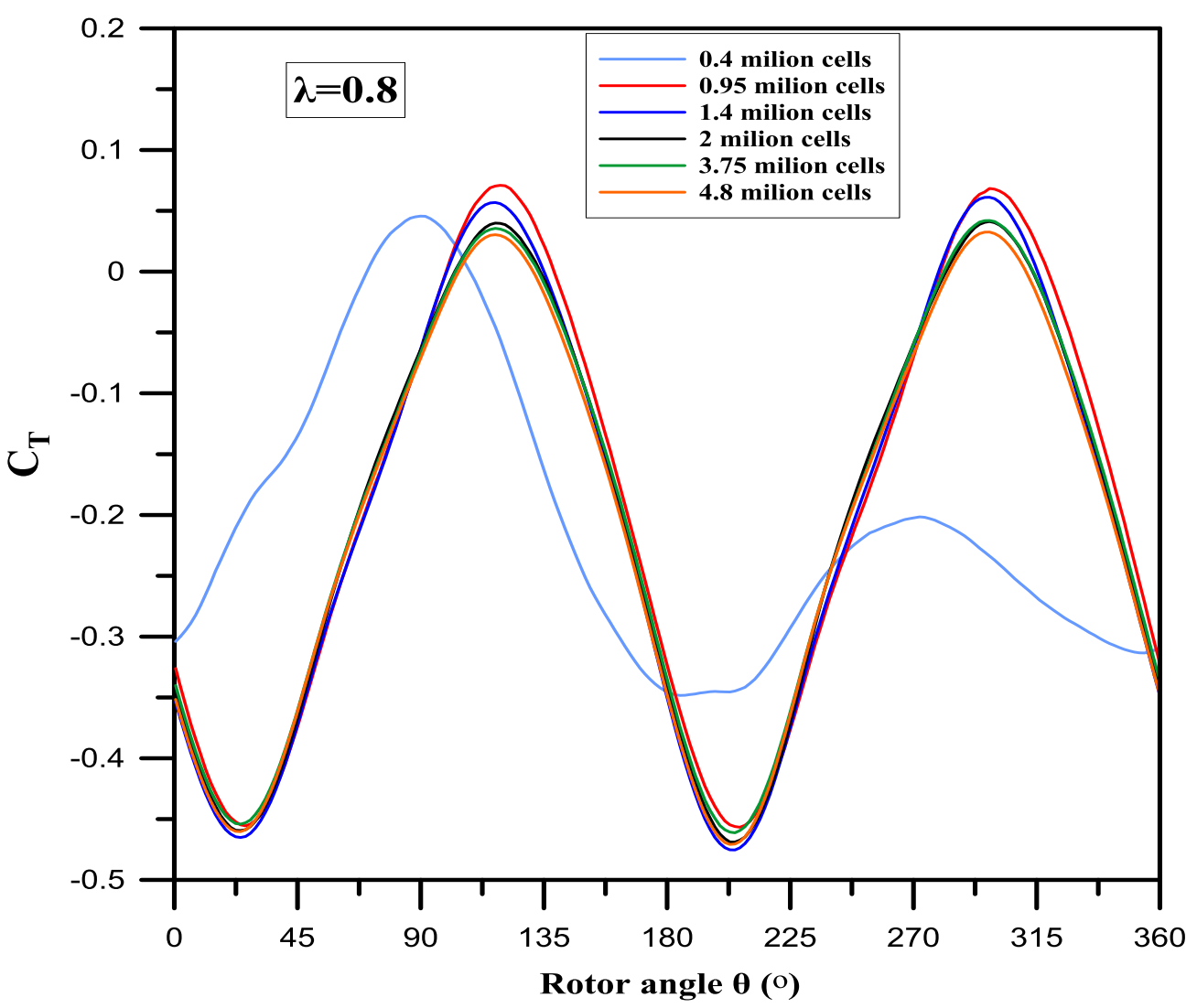

Fig.5. Effect of grid resolution on torque coefficient over a complete revolution at tip speed ratio $\lambda=0.8$ for conventional rotor 


$$
R^{2}=1-\frac{\sum\left(\phi_{\operatorname{Exp}}-\phi_{\text {pred }}\right)^{2}}{\sum\left(\phi_{\operatorname{Exp}}-\bar{\phi}_{\operatorname{Exp}}\right)^{2}}
$$

where

$$
\bar{\phi}_{\operatorname{Exp}}=\frac{\sum_{i=1}^{n} \phi_{\operatorname{Exp}}}{n}
$$

where $\mathrm{n}$ is the number of the experimental results.

The values of the correlation coefficient for the conducted turbulence models are shown in Table 1. The results obtained in Table1, indicate that the RNG $\mathrm{k}-\varepsilon$ turbulence model has the highest value of $\mathrm{R}^{2}$. Hence, the RNG $\mathrm{k}-\varepsilon$ turbulence model has more accurate results compared with the other studied models. This encourages the authors to extend the simulation using the RNG $\mathrm{k}-\varepsilon$ as a suitable turbulence model for all present simulations.

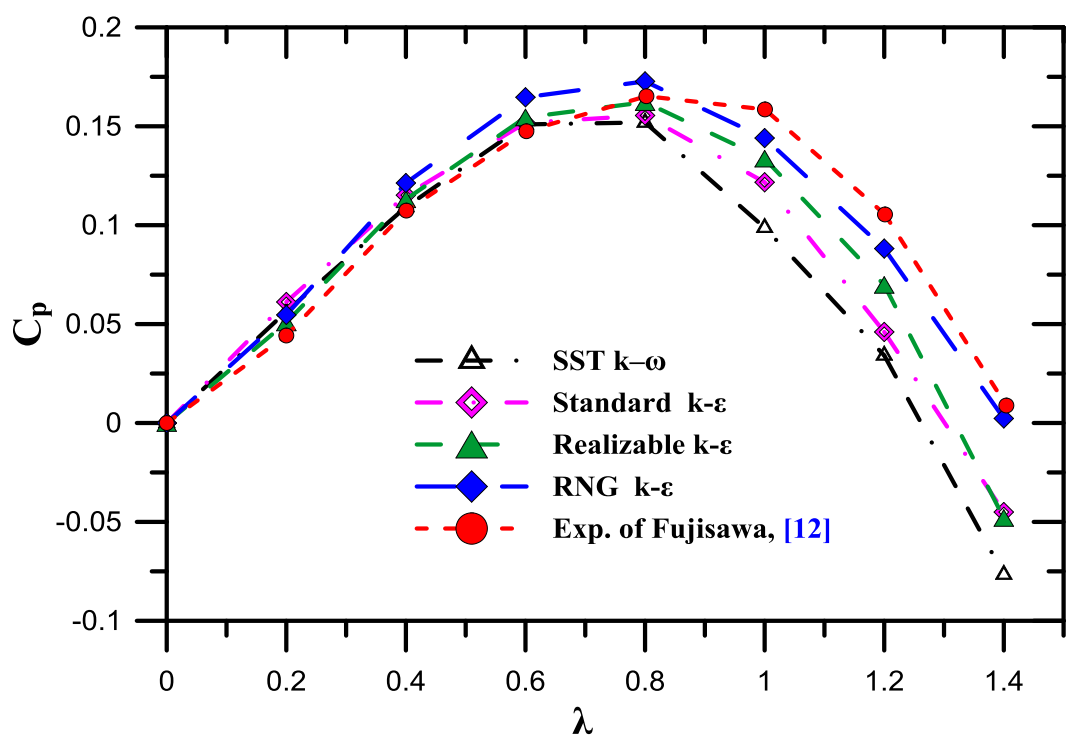

Fig.6. Comparisons between results of the conducted turbulence models and experimental results published by Fujisawa, [12]

Table 1. The correlation coefficient $\left(R^{2}\right)$ for the conducted turbulence models

\begin{tabular}{l|l}
\hline \hline Turbulence model & $\mathrm{R}^{2}$ \\
\hline SST $\mathrm{k}-\omega$ & 0.457 \\
standard $\mathrm{k}-\varepsilon$ & 0.723 \\
realizable $\mathrm{k}-\varepsilon$ & 0.82 \\
$\mathrm{RNG} \mathrm{k}-\varepsilon$ & 0.961 \\
\hline \hline
\end{tabular}


In the present study, four Savonius wind rotors are tested which are, the conventional rotor, the conventional helical rotor with twist, the modified rotor and the modified helical rotor with twist. The geometry details for each rotor were discussed previously in section 2. Figs. 7 and 8 show the variation of the average power and torque coefficients with tip speed ratios for all the rotors examined in this study. It is observed that the modified helical rotor with twist, introduced in this study, significantly enhanced the turbine performance and increased the output power gained from the turbine. It reaches its maximum $\mathrm{C}_{\mathrm{p}}$ of about 0.22 at $\lambda=0.8$ and its maximum $\mathrm{C}_{\mathrm{T}}$ of about 0.41 at $\lambda=0.4$. The values of the maximum power and torque coefficients $\left(\mathrm{C}_{\mathrm{p}, \max }\right.$ and $\left.\mathrm{C}_{\mathrm{T}, \max }\right)$ and the corresponding tip speed ratio are presented in Table 2 .

The variation of the torque coefficient during a complete cycle from $\theta=0$ to $360^{\circ}$ at $\lambda=0.4$ for the conventional and modified helical rotors with twist is shown in Fig. 9. It is observed that modified helical rotor with twist attains higher torque coefficient than conventional helical rotor with twist at all rotor angles except from $\theta=55$ to $105^{\circ}$ and $\theta=235$ to $285^{\circ}$.

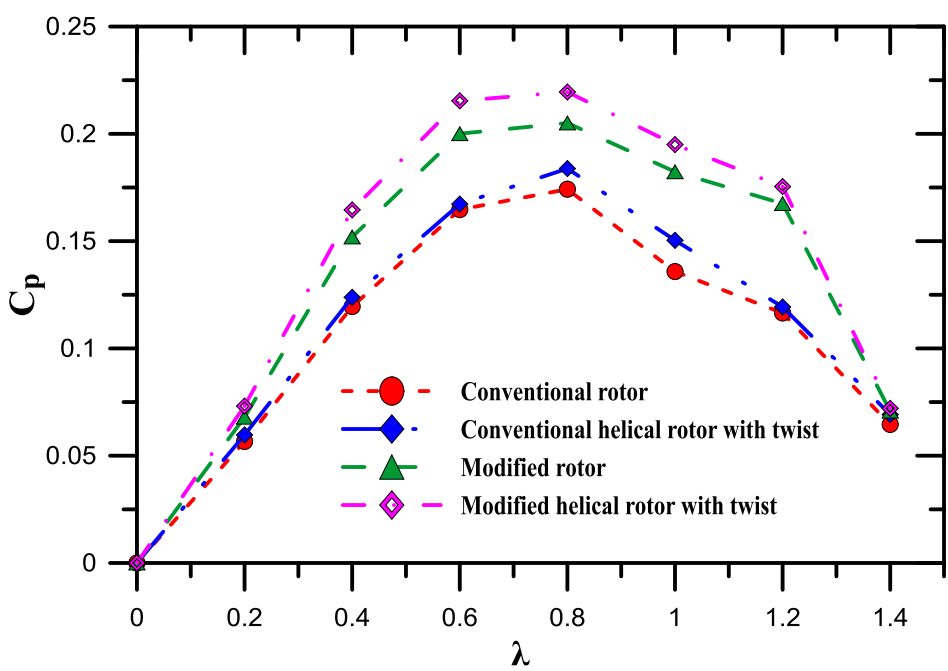

Fig. 7. The variation of the average power coefficient with tip speed ratio for the rotors examined in this study

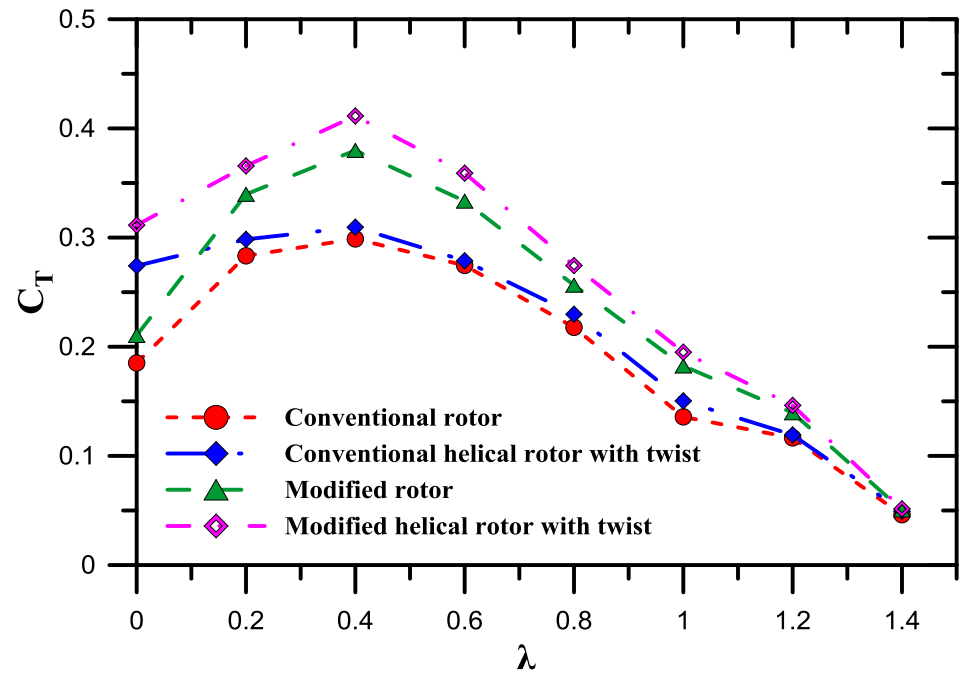

Fig. 8. The variation of the average torque coefficient with tip speed ratio for the rotors examined in this study 


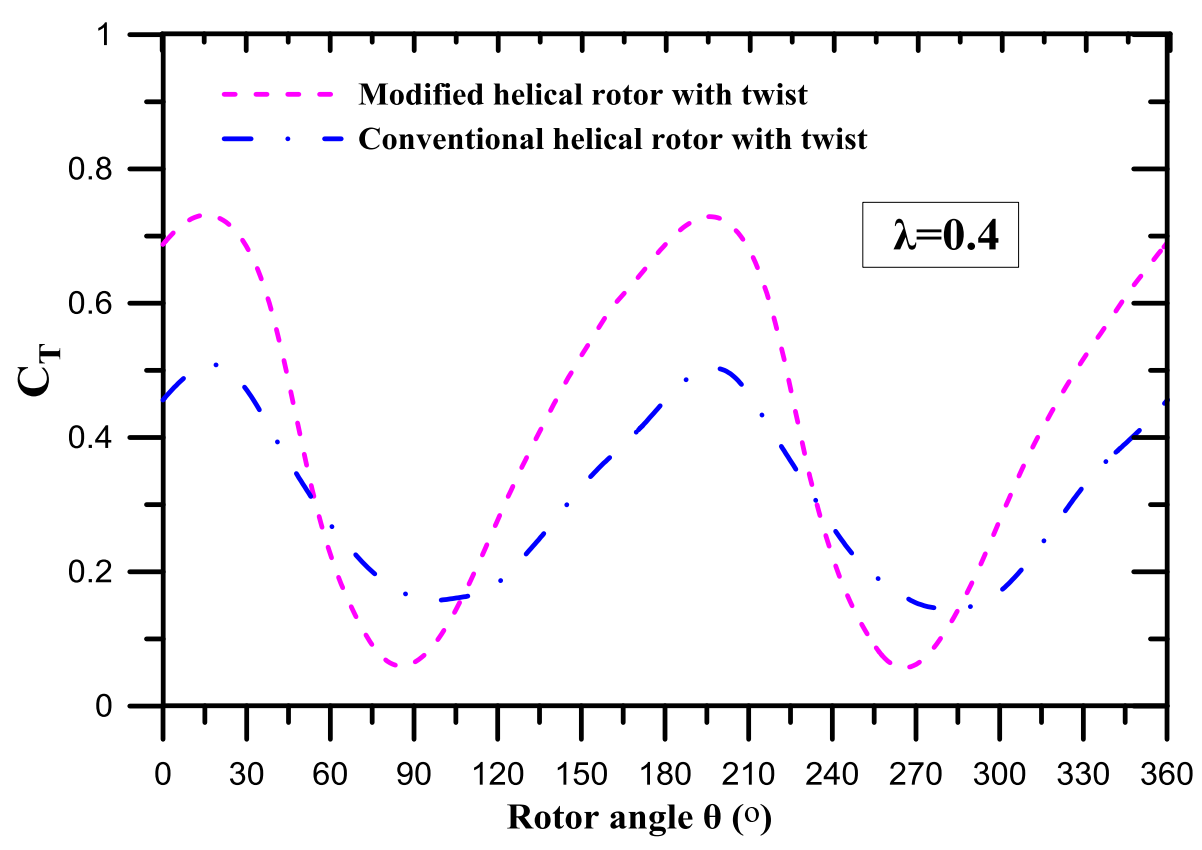

Fig. 9. Torque coefficient versus angular position over one revolution

Fig. 10 illustrates the contribution of the advancing and returning blades in the total torque coefficients for a complete cycle from $\theta=0$ to $360^{\circ}$ at $\lambda=0.2,0.4,0.6,0.8,1.0$ for the modified helical rotor with twist. It is observed that the total $\mathrm{C}_{\mathrm{T}}$ values are positive at all rotor angles for $\lambda=0.2,0.4,0.6$. Negative $\mathrm{C}_{\mathrm{T}}$ values occurred at $\lambda>0.6$ at some rotor angles and increase with the increase of the value of $\lambda$. Table 3 shows the average $C_{T}$ values within $180^{\circ}$ rotor angles for the advancing, returning and total rotor blades at different tip speed ratios for the modified twisted rotor. It can be noticed that the average $C_{T}$ values of the advancing blade decrease with the increase of $\lambda$ (rotation speed). However, the average $C_{T}$ values of the returning blade are initially decreased from $\lambda=0.2$ to 0.4 , then increase at $\lambda>0.4$. The average $C_{T}$ of the returning blade at $\lambda=0.4$ is positive unlike all the other values of $\lambda$ and that might be the reason for the maximum $\mathrm{C}_{\mathrm{T}}$ occurs at this $\lambda$.

Table 2. The values of maximum power and torque coefficients and the corresponding tip speed ratio

\begin{tabular}{l|c|c|c|c}
\hline \hline Rotor & $\mathrm{C}_{\mathrm{p}, \max }$ & $\begin{array}{c}\lambda \text { corresponding to } \\
\mathrm{C}_{\mathrm{p}, \max }\end{array}$ & $\mathrm{C}_{\mathrm{T}, \max }$ & $\begin{array}{c}\lambda \text { corresponding to } \\
\mathrm{C}_{\mathrm{T}, \max }\end{array}$ \\
\hline Conventional rotor & 0.174 & 0.8 & 0.298 & 0.4 \\
Conventional twisted rotor & 0.183 & 0.8 & 0.31 & 0.4 \\
Modified rotor & 0.205 & 0.8 & 0.38 & 0.4 \\
Modified twisted rotor & 0.22 & 0.8 & 0.41 & 0.4 \\
\hline \hline
\end{tabular}



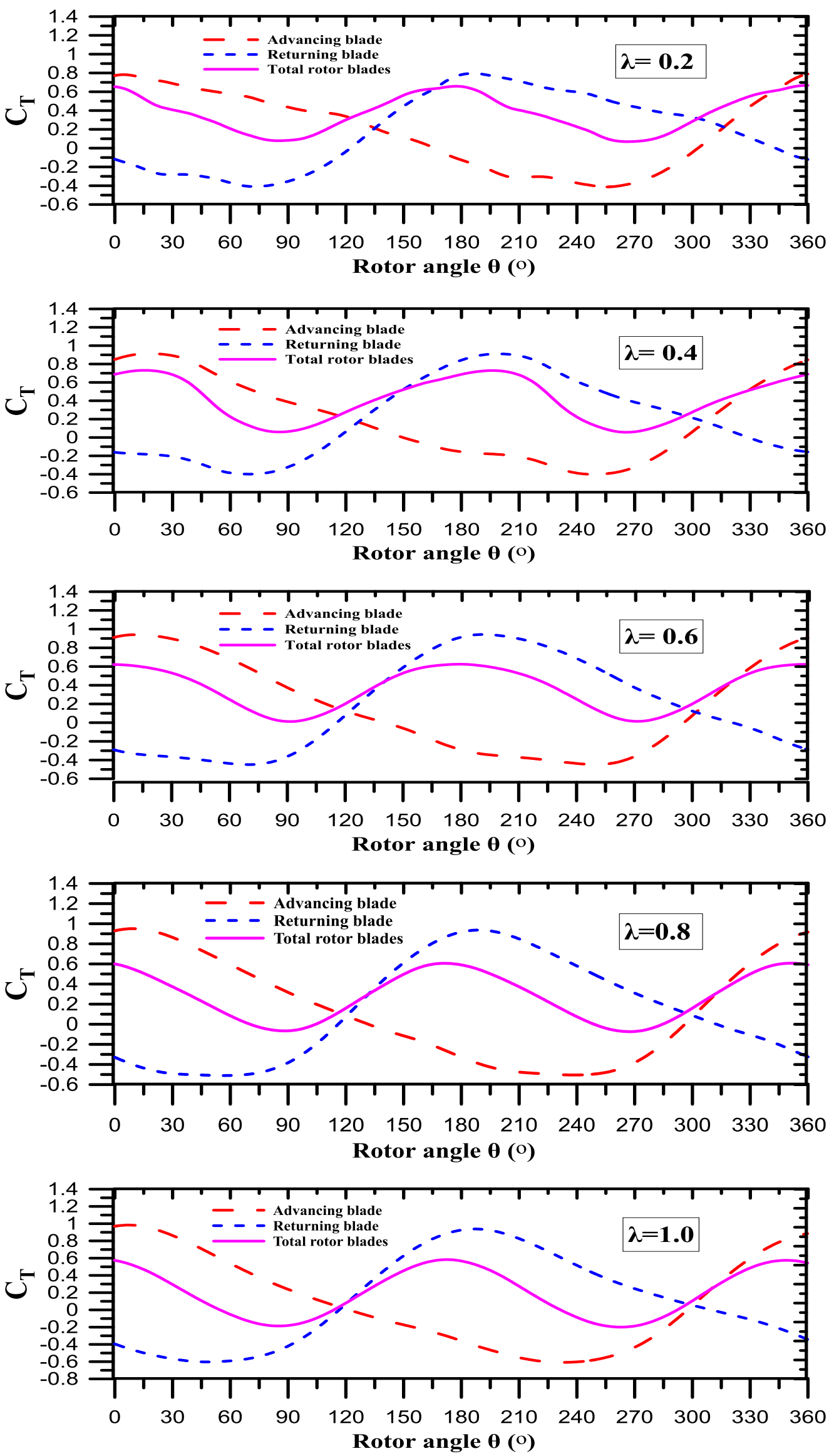

Fig. 10. The contribution of the advancing and returning blades in the total torque coefficients over one revolution of modified helical rotor with twist 
Table 3. The average $C_{T}$ values within $180^{\circ}$ rotor angles for the advancing, returning and total rotor blades at different

tip speed ratios for the modified helical rotor with twist

\begin{tabular}{c|c|c|c}
\hline \hline$\lambda$ & $\begin{array}{c}\text { Advancing } \\
\text { blade }\end{array}$ & $\begin{array}{c}\text { Returning } \\
\text { blade }\end{array}$ & $\begin{array}{c}\text { Total rotor } \\
\text { blades }\end{array}$ \\
\hline 0.2 & 0.779 & -0.046 & 0.368 \\
0.4 & 0.41 & 0.0023 & 0.413 \\
0.6 & 0.39 & -0.032 & 0.36 \\
0.8 & 0.346 & -0.07 & 0.276 \\
1.0 & 0.302 & -0.104 & 0.197 \\
\hline \hline
\end{tabular}

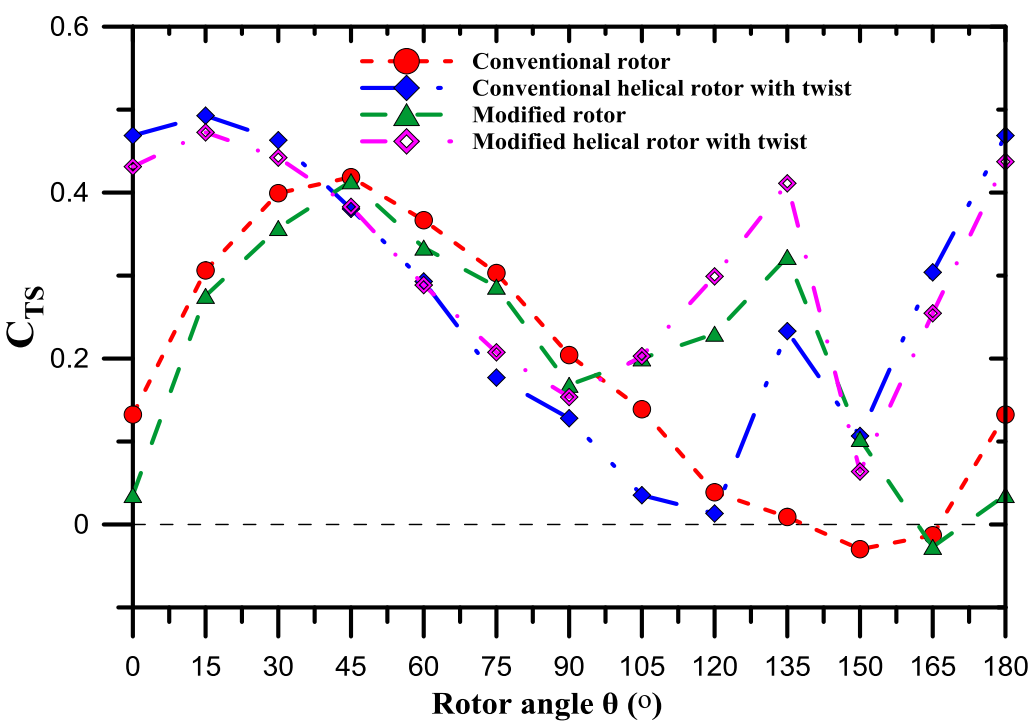

Fig. 11. The variation of static torque coefficient $C_{T S}$ versus rotor angles for all rotors examined in this study

Table 4. The average static torque coefficient within $180^{\circ}$ rotor angles for the rotors examined in this study

\begin{tabular}{l|l}
\hline \hline Rotor shape & Average $\mathrm{C}_{\mathrm{TS}}$ \\
\hline Conventional rotor & 0.185 \\
Conventional twisted rotor & 0.274 \\
Modified rotor & 0.21 \\
Modified twisted rotor & 0.311 \\
\hline \hline
\end{tabular}




\section{Conclusions}

The performance of a helical modified Savonius wind rotor with a twist angle of $45^{\circ}$ is numerically investigated. The solution obtained using the RNG $\mathrm{k}-\varepsilon$ model is found to give more accurate results, as compared with published experimental measurements. The results of the present modified helical rotor with twist are compared with the conventional helical rotor with twist, the modified rotor without twisting and the conventional rotor. The rotors tested in the present study have an aspect ratio of 1.0 and overlap ratio of 0.15 . The modified helical rotor with twist is found to attain the highest $C_{p}$ of 0.22 , as compared to 0.174 for the conventional rotor, with a performance gain of $26.4 \%$. Furthermore, this positive effect of the introduced rotor is also observed for the torque coefficient. For the modified helical rotor with twist, the $C_{T}$ is always positive at all rotor angles except for a narrow range at $\lambda>0.6$. It is found also that, there is no negative static torque coefficient $\mathrm{C}_{\mathrm{TS}}$ for the conventional and modified helical rotor with twist unlike the conventional and modified rotors without introducing twist. Furthermore, the modified helical rotor with twist shows a significant rise in the $\mathrm{C}_{\mathrm{TS}}$ at rotor angles of low $\mathrm{C}_{\mathrm{TS}}$ for other tested rotors.

To conclude, there is a significant improvement in the rotor performance, including $\mathrm{C}_{\mathrm{P}}, \mathrm{C}_{\mathrm{T}}$ and $\mathrm{C}_{\mathrm{TS}}$, when using the present modified helical Savonius rotor with twist.

\section{References}

[1] S. Eriksson, H. Bernhoff, and M. Leijon, "Evaluation of different turbine concepts for wind power," Renew. Sustain. Energy Rev., vol. 12, no. 5, pp. 1419-1434, 2008.

[2] J. V. Akwa, H. A. Vielmo, and A. P. Petry, "A review on the performance of Savonius wind turbines," Renew. Sustain. Energy Rev., vol. 16, no. 5, pp. 3054-3064, 2012.

[3] S.-H. Yoon, H.-C. Lim, and D.-K. Kim, "Study of several design parameters on multiblade vertical axis wind turbine," Int. J. Precis. Eng. Manuf., vol. 14, no. 5, pp. 831837, 2013.

[4] S. J. Savonius, "The S-rotor and its applications," Mech. Eng,vol. 53, pp.333-338, 1931.

[5] V. J. Modi, N. J. Roth, and A. Pittalwala, "Blade Configurations and Performance of the Savonius Rotor with Application to an Irrigation System in Indonesia," Trans. ASME, vol. 105, pp. 294-299, 1983.

[6] R. Vishwakarma, "Savonius rotor wind turbine for water pumping an alternate energy source for rural sites," J. Institution of Engineers (India), vol. 79, pp.32-40, 1999.

[7] R. E. Sheldahl, L. V. Feltz, and B. F. Blackwell, "Wind tunnel performance data for two- and three-bucket Savonius rotors," J. Energy, vol. 2, no. 3, pp. 160-164, 1978.

[8] A. J. Alexander and B. P. Holownia, "Wind Tunnel Tests On a Savonius Rotor," J. Ind. Aerodyn., vol. 3, pp. 343-351, 1978.

[9] V. Modi and M. Fernando, "On the performance of the Savonius wind turbine," J. Solar Energy Engineering, vol. 111, no. 1, pp. 71-81, 1989.

[10] O. O. Mojola, O. E. Onazanya, "Performance testing of a Savonius windmill rotor in shear flows," J. Wind Eng. Ind. Aerodyn., vol. 8, no. 2, pp. 109-121, 1984.

[11] O. O. Mojola, "On the aerodynamic design of the savonius windmill rotor," J. Wind Eng. Ind. Aerodyn., vol. 21, no. 2, pp. 223-231, 1985.

[12] N. Fujisawa, "On the torque mechanism of Savonius rotors," J. Wind Eng. Ind. Aerodyn., vol. 40, no. 3, pp. 277-292, 1992.

[13] J. V. Akwa, G. Alves Da Silva, and A. P. Petry, "Discussion on the verification of the overlap ratio influence on performance coefficients of a Savonius wind rotor using computational fluid dynamics," Renew. Energy, vol. 38, no. 1, pp. 141-149, 2012.

[14] M. H. Mohamed, G. Janiga, E. Pap, and D. Thévenin, "Optimal blade shape of a modified Savonius turbine using an obstacle shielding the returning blade," Energy Conversion and Management, vol. 52, no. 1, pp. 236-242, 2011. 
[15] T. Ogawa and H. Yoshida, "Effects of a deflecting plate and rotor end plates on performance of Savonius type wind turbine," Bulletin JSME, vol. 29, no. 253, pp. 21152121, 1986.

[16] K. S. Jeon, J. I. Jeong, J. K. Pan, and K. W. Ryu, "Effects of end plates with various shapes and sizes on helical Savonius wind turbines," Renew. Energy, vol. 79, no. 1, pp. 167-176, 2015.

[17] N. Fujisawa and F. Gotoh, "Visualization study of the flow in and around a Savonius rotor," Exp. Fluids, vol. 12, no. 6, pp. 407-412, 1992.

[18] M. A. Kamoji, S. B. Kedare, and S. V. Prabhu, "Performance tests on helical Savonius rotors," Renew. Energy, vol. 34, no. 3, pp. 521-529, 2009.

[19] H. E. Gad, A. A. Abd El-Hamid, W. A. El-Askary and M. H. Nasef, "A New Design of Savonius Wind Turbine: Numerical Study," CFD Letters, vol. 6, no.4, pp. 144-158, 2014.

[20] A. Damak, Z. Driss, and M. S. Abid, "Experimental investigation of helical Savonius rotor with a twist of $180^{\circ}$," Renew. Energy, vol. 52, pp. 136-142, 2013.

[21] J. H. Lee, Y. T. Lee, and H. C. Lim, "Effect of twist angle on the performance of Savonius wind turbine," Renew. Energy, vol. 89, pp. 231-244, 2016.

[22] Fluent, 2015. User's Guide Fluent 15.0. Fluent Incorporated, Lebanon, NH.

[23] J. Maindonald and W. J. Braun, Data Analysis and Graphics Using $R$ - an ExampleBased Approach, $3^{\text {rd }}$. ed., 2003. 